\title{
Migrant women's knowledge and perceived sociocultural barriers to cervical cancer screening programme: a qualitative study of African women in Poland
}

This article explores both the knowledge and perception of African women about the importance of screening as a recommended health action to counter the growing rate of cervical cancer in women. The theoretical framework is influenced by the postulations of behavioural theories, sociology of health and the health belief model (HBM) on how people perceive health issues such as cervical cancer and its screening measures. In addition, this study tries to explore the acculturation challenges involved in migration, which adversely affects health knowledge and behaviour of African women. To achieve this, one focus group discussion was conducted with twelve women between the ages of 25 and 54 years old from Egypt, Eritrea, Kenya and Nigeria to share their knowledge of cervical cancer screening programmes in Poland. They constituted a mixture of women from different parts of Africa with cultural differences and different belief systems. Little or no in-depth understanding of Polish language, lack of in- formation about the disease and its screening methods, lack of understanding of the Polish health care systems and social economic factors were issues discussed by these women as sociocultural barriers to their non-participation in the organised cervical cancer screening programme in Poland. Based on this study, migrant women lack adequate information about cervical cancer, its causes, risk factors and its screening methods. Therefore, this study proposes that good understanding of health care systems, language translation support in the health care system, health awareness campaigns and social relationships are important motivating factors that could encourage migrant women to participate in the cancer screening programmes in Poland.

\section{KEY WORDS}

cervical cancer screening; health information; health belief model; migration; sociocultural barriers

ORganization - Polish Academy of Sciences, Warsaw, Poland

AUthors' Contributions - A: Study design - B: Data collection - C: Statistical analysis - D: Data interpretation .

E: Manuscript preparation · F: Literature search · G: Funds collection

CORResponding AUthor - Omoye Mary Akhagba, Polish Academy of Sciences, 72 Nowy Swiat Str., 00-330 Warsaw,

Poland, e-mail: oakhagba@sns.edu.pl

TO CITE THIS ARTICLE - Akhagba, O. M. (2017). Migrant women's knowledge and perceived sociocultural barriers to cervical cancer screening programme: A qualitative study of African women in Poland. Health Psychology Report,

5(3), 263-271. doi: https://doi.org/10.5114/hpr.2017.65238 


\section{BACKGROUND}

Amongst all the kinds of cancer prevalent in the world today, cervical cancer is the second deadliest disease that affects women after breast cancer and is responsible for large numbers of deaths globally despite being curable (WHO, 2014b). Cervical cancer according to the American Cancer Society (2011) begins in the cervix, the lower part of the uterus of the female reproductive organ, which is also known
Omoye Mary Akhagba as the uterine cervix. It is a malignant tumour in the tissues of the cervix that occurs when abnormal cells in the cervix turn into cancer cells and these cancer cells break through the surface cells (epithelium) of the underlying tissue (stroma) of the cervix (IARC, 2012). One of the major causes of cervical cancer has been attributed to the human papillomavirus (HPV), which is the most widespread sexually transmitted disease in sexually active adults (Koutsky, 1997). In the campaign for the reduction of death rates of cervical cancer, the World Health Organization (2014a) proposed that early detection of cervical cancer increases the chances for successful treatment, and there are two major components of early detection of cervical cancer, which are education to promote early diagnosis and screening. The WHO (2014a) explained that "cervical cancer is a largely preventable disease" (p. 25). More so, an increase in the level of awareness of possible warning signs of cervical cancer among the general public could have a great impact in treating the disease (Ostrowska, 2007).

The American Society for Colposcopy and Cervical Pathology and the American Clinical Society (2012) stated that women between the ages of 25 and 45 are prone to the risk of cervical cancer and further recommended that women aged 21 years and above should commence screening programmes because they are at risk. Screening is aimed at early detection as well as channelling preventive measures to avert the manifestation of this virus in the cervix caused by the human papillomavirus (IARC, 2005). The cervical cancer screening result varies among women but does not necessarily translate to cancer. For instance, Cancer Research UK (2016) states that 1 in $20(5 \%)$ women in the United Kingdom usually receive an abnormal test result after cervical cancer screening, which means there could be some changes in the cells of the cervix but there is always room for re-examination to prove the growth of this virus. Some results often at times translate to mean a false- positive result or false-negative result. In such cases, there is a need for re-examination, but out of fear and other unexplainable reasons some women are hesitant in undertaking a retest and in the long run it might lead to full blown cancer of the cervix.

\section{CERVICAL CANCER AS A GLOBAL ISSUE}

One of the major concerns about the rise in the cases of cervical cancer is the decline in the number of women who have been screened in the United States since 2008 . Consequently, more than $50 \%$ of new cases of cervical cancer were diagnosed among women who have never undergone screening in the last five years (Behavioural risk factor surveillance system, 2012). Even with the efficiency of screening in the United States, more than $10 \%$ of women have not been screened in the past 7 years (CDC, 2014).

Cervical cancer remains a worrisome global issue of concern for most women living in Poland (Januszek-Michalecka, Nowak-Markwitz, Banach, \& Spaczynski, 2013; Jach, 2014). The death rate in Poland remains unchanged at 1800 deaths annually in the last 10 years (Samolinski, 2012).

One of the challenges in overcoming cervical cancer cases in Africa is the late diagnosis until the progression of the disease because there are no organised and structured early detection programmes and screening facilities available in public health care systems (American Cancer Society, 2011). Afri-Dev info (2014) data on cervical cancer cases show the high rates of this disease in 16 African countries, with Malawi (75.90\%) recording the highest cervical cancer incidence in the region. Moreover, is it the leading cause of deaths among women in Malawi with $39.00 \%$ of the death rate recorded (WHO, 2014e). Globally, about 266,000 women die of cervical cancer every year from Eastern and Central Africa and in other 45 countries in the world (WHO, 2014d). These countries have been categorized as low income countries to include the sub-Saharan Africa, Asia-India Central and South America. This cause of deaths is lack of effective and organised prevention, early detection and treatment measures in place for women in public hospitals. Hence, there is late diagnosis of cervical cancer and an increased mortality rate (WHO, 2014c; IARC, 2012).

This study draws its arguments from postulations of the health belief model's focusing on migration as a perceived barrier to cervical screening as it relates to women's health, that is, migration as a barrier to positive health behaviour. Migration is borne out of the desire for people to move around in search of basic needs and satisfaction, and the desire to improve one's lot in life, and it is not unjustifiable to have this mission to migrate for such improvement in personal development and general wellbeing (IOM, 2015). These expectations are very good but partly realized. There are positive benefits in the process of migration which should not be ignored.

Migration is a social determinant of health (IOM, 2006). However, the process of migration can be traumatic and expensive, and it sometimes leads to death as a result of unbearable conditions. While in 
the process of migration, people encounter immigration-related stressors that intersect between cultural changes, legal status discrimination and acculturation stress (Torres \& Wallace, 2013). These geographical and cultural changes have resulted in deteriorating health status such as mental health and physical stress of people resettling in new environments and societies, which Finch, Frank, and Vega (2004) regard as acculturation stress. Torres and Wallace's (2013) research on the health of Latino immigrants in the United States emphasizes that most of the health problems faced by Latino immigrants are immigration-related stressors. In other words, migration also exposes people and especially women to social and health risk while trying to cope with family if they have to work for longer hours even at night to cater for the family with less time spent on themselves (WHO, 2010).

Participation of migrant women in cervical cancer screening programmes could be hindered by lack of knowledge in the structure of health care systems as well as lack of experience with the NHS structure in host countries (O’Donnell, Higgins, Chauhan, \& Mullen, 2008; Quan et al., 2006). One of the consequences of migration is that it has a great deal of issues of accessible health care programmes and services as well as the availability of suitable cultural and linguistic care for women from other countries (Jackowska et al., 2012). There is a challenge for women who migrate from their countries of origin to another who may find it difficult to understand the social structure of their new societies in a way that hinders their adaptation to the system, which eventually leaves them unscreened.

According to the WHO (2014c) country report on cervical cancer cases, most developing countries are yet to commence cervical cancer screening in all public hospitals, while developed countries, including Poland and other European countries, offer cervical cancer screening for women who possess valid health insurance in all public hospitals. Poland commenced organised cervical cancer screening in 2007 in accordance with the European Guidelines (EuG) for prevention of cervical cancer in women (WHO, 2014f). Cervical cancer screening in Poland is organised by the Ministry of Health and the National Health Fund (NHF). This screening process begins with a written invitation to all women aged 25-59 years (Nowakowski et al., 2015).

Knowledge about the risk of cervical cancer, screening and prevention measures is quite low in immigrant women. A study conducted by Azerkan et al. (2015) among Danish and Norwegian immigrant women in Sweden found out that women do not actually understand the essence of the Pap smear test if there were no precancerous symptoms. The essence of the Pap test is to detect and diagnose precancerous signs in the woman's cervix before it results in advanced cancer (Leyden et al., 2005). Also known as cervical cytology, this screening procedure helps to detect malignant lesions and other abnormalities in the cervix (Nygård, Skare, \& Thoresen, 2002).

It is considered that not all women are favourably disposed to attend screening in various countries, especially women who migrate to other countries due to various reasons, because migration comes with sociocultural changes and adaptation, as new attitudes are developed and accepted; people find it very difficult to learn a new language, lifestyle and beliefs, which in turn has a great impact on the larger society.

In addition, there is lack of familiarity with various preventive health care systems among migrant women within their host countries because some feel that a person does not necessarily have to visit the hospital unless when sick and due to their perception that such visits usually incur additional financial expenses as compared to their home countries with a different health care system and operations.

Sociocultural adaptation to new cultures and environment pose a serious barrier to healthy living as people move from their comfort zones to other places where they have to face challenges such as legalization of their residency in new countries, good understanding of social structures, language, harsh climatic conditions, stereotypes in the society and overall acculturation, which have adverse effects on social relationships. Migrants, irrespective of their legal status in the host country, often experience and complain about the immigration laws, its restrictions, financial insecurity, language, health literacy on preventive care and equal rights and access to social services (Carrie \& Bandolin, 2011). When issues such as health and treatment arise, migrants face a multitude of barriers to getting adequate and urgent attention due to some factors emanating from both the migrant and the host society.

Schleicher (2007) stated that the number of years spent by migrants in the United States affects their likelihood of undergoing cervical cancer screening due to language and cultural barriers and difficulty in accessing healthcare systems. In addition, the possession of valid health insurance hinders access to the health care system, which most often leads to late diagnosis of cervical cancer as a result of personal beliefs of one's state of health and finances. Research reveals that socioeconomic and insurance status directly impact access to the healthcare system, in which lack of health insurance could be associated with the diagnosis of late stage cervical cancer (Schleicher, 2007).

\section{AIMS OF THE STUDY}

This study aims at exploring the knowledge and perceptions of African women about cervical cancer and its screening programmes available in Poland. In ad-
Migrant women's knowledge and perception of cervical cancer screening in Poland 
dition, it further explains the sociocultural barriers preventing African women from attending cervical cancer screening in Poland.

\section{THEORETICAL FRAMEWORK - HEALTH BELIEF MODEL (HBM)}

The postulations of the health belief model are applicable in this study in order to explain the knowledge, beliefs and perception about risk factors of cervical cancer and screening methods on health-related behaviours among migrant women living in Poland.

The health belief model by Rosenstock (1974) explains how behaviour can be modified on issues such as preventive measures for cancer and other diseases. This theory states the reason an individual may accept or reject preventative health services or adopt healthy behaviours and cultures. This model was formulated to predict the likelihood of a person taking recommended health action and to explain the process of an individual's thinking and motivation about seeking health solutions, that is, focusing on social cognition (Ajzen, 1998). It further postulates that people will respond promptly to health-related messages when they perceive severity and risk of developing a poor health condition, and such risk can be avoided by taking a recommended health action. The six-stage postulations of this model (Figure 1) begin with the level of information an individual might have about the risk factors or susceptibility to a disease; this is what Rosenstock (1974) refers to as perceived susceptibility. If a person does not have adequate knowledge about the disease, there is no way such a person will feel vulnerable to contracting such diseases. In other words, how do migrant women know their vulnerability to cervical cancer if they have no clue about the disease and its preventive measures? Thus, lack of information does not help women living away from their home countries to receive adequate support about cancer treatment until its manifestation.

The second postulation, perceived severity, refers to how an individual feels the seriousness of contracting an illness or disease, especially when it is undiagnosed or untreated. Hence, the person often considers both some social and medical consequences such as pain, death, disability, loss of family life, social relationship, integration, etc. A person with information about the disease later tends to evaluate the severity in order to seek assistance if necessary. One of the strengths of the health belief model lies in the analysis of health behaviour and practice by constructing its applicability to predict health outcomes (Conner, 2010).

Perceived benefits - at this stage, the person perceives the effectiveness of various actions available in order to reduce the threat of illness or disease (or find a cure). Facts are considered and evaluated based on what the person perceives to be susceptible and beneficial, such that the person would accept the recommended health action if it was perceived as beneficial.

Perceived barriers - at this point, there are some obstacles that prevent the individual from performing a recommended health action, one of which is

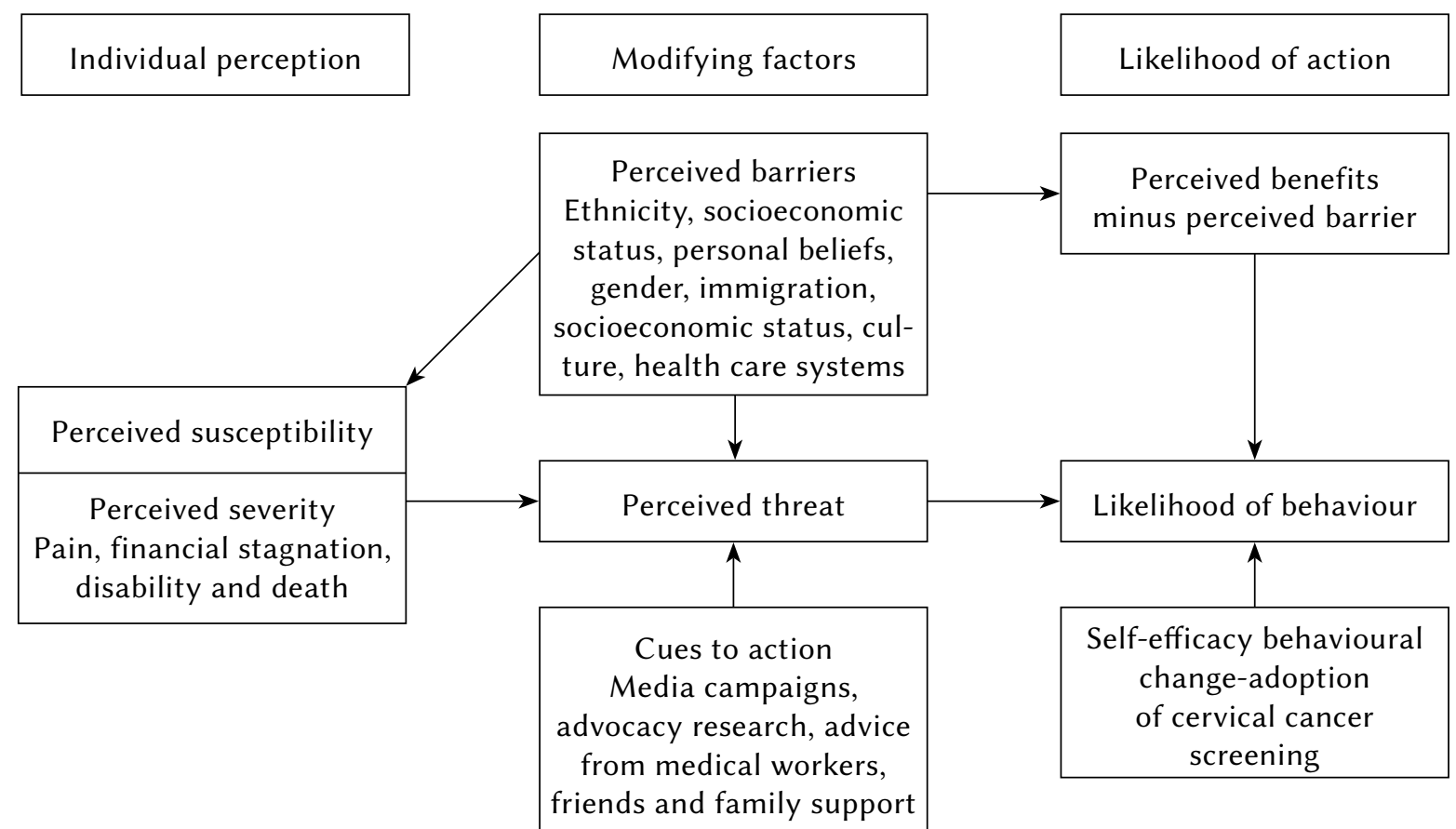

Note. Adapted from Rosenstock (1974). Health Belief Model and preventive health behaviour. Health Education Monography, 2, $354-386$.

Figure 1. Health belief model in relation to cervical cancer screening. 
considered here and is migration and the problem of acculturation in new societies. Nevertheless, the individual also considers issues such as cost implications, pain, time and convenience of such health action. Migration comes with sociocultural changes and adaptation, as new attitudes are developed and accepted; people find it very difficult to learn a new language, lifestyle and beliefs, which in turn has a great impact on the larger society. Because the health of every woman is important as they contribute to growth of the family, community and the society at large, it is important to take into account every behavioural change and adaptation of women.

Cue to action refers to the important aspect of stimulating an individual's decision making process to accept a recommended health action. These cues can be internal, which include symptoms or signs indicating cancer, e.g., lump in the breast, uncontrollable mucus or bleeding from the cervix, etc. or external support from medical or community health workers, e.g., advice from others, illness of family member, media campaigns, etc.

Self-efficacy refers to the level of an individual's overall conviction to successfully perform the recommended health behaviour such as cancer screening, quit cigarette smoking, HIV/AIDS testing, vaccination, etc. Bandura (1997) explained that one's ability to undertake an action may produce the desired outcome which is believed to have modified negative health behaviours such as quitting cigarette smoking, weight loss, and maintaining healthy dietary habits.

\section{PARTICIPANTS AND PROCEDURE}

This research study was conducted to explore the knowledge and perception of migrant women about cervical cancer and other health-related issues. The main question in this study focused on the participants' knowledge about cervical cancer screening, its benefits and the sociocultural issues that impedes migrant women in the participation of the screening programmes in Poland.

Sampling technique. Participants were purposively selected based on their countries of origin and immigration status in Poland. A focus group discussion was conducted in English language with twelve African migrant women aged 25-54 years old from Egypt, Kenya, Nigeria and Eritrea to share their experiences and knowledge of cervical cancer screening programmes in Poland. They constituted a mixture of women from different parts of Africa with cultural differences and different belief systems comprising Arab Muslims and Christians from Egypt, Orthodox Christians from Eritrea, and Catholics from Nigeria and Kenya.

All twelve participants had a formal education from vocational education up to postgraduate level and were very literate in writing and speaking. They could all speak English and other languages such as Swahili, Arabic and Tigrigna. Regarding age and marital status, all but one of the women from Egypt are widows, while the others are single or married. Their age falls between 25 and 54 years old.

In this focus group discussion, the majority of women were Kenyans and Eritreans who had been married to Polish men and understood the Polish health care system but had not visited any hospital for cervical cancer screening in Warsaw. Other women from Nigeria and Egypt could not speak Polish and did not feel the need to visit the hospitals for cancer screening, but they were willing to attend cancer screening programmes in Poland if motivated in the near future. One of the participants from Eritrea understood a little Polish because she had lived in Poland for over five years but did have a sense of integration into Polish society. Even if she had stayed for a longer period she expressed mixed feelings about how she would get treated in the hospital both in the public and private centres.

Recruitment and participation. These women voluntarily signed up for this focus group discussion at the monthly women's meeting held at the Foundation for Somalia, a non-governmental organization in Warsaw, Poland. However, some did not agree to the audio recording of the discussion, so answers to the questions were written on a paper for anonymity and confidentiality of the participants. "African woman" is assigned to each participant for anonymity and confidentiality purposes.

Location. The discussion took place at the Foundation for Somalia, Warsaw, Poland with a group of migrant women under the project 'Enterprising Migrant Women's Club'.

\section{ANALYSIS}

All data were manually recorded because the participants objected to any form of digital recordings including taking photos. Responses were typed and analysed using the computer program MAXQDA. Categories were created using the six postulations of the health belief model as the main code labels and subcodes to find related phrases to interpret alongside this theoretical framework. This framework-based analysis (Ritchie, Spencer, \& O'Connor, 2003) helped to identify emerging themes and subthemes for the discussion of findings in the study.

\section{FINDINGS}

The findings of this study expound the perceptions of the participants on issues generally relating to
Migrant women's knowledge and perception of cervical cancer screening in Poland 
barriers to health care, health beliefs, perception of cancer as a deadly disease and their knowledge about cervical cancer screening, which are presented below.

\section{PERCEIVED SUSCEPTIBILITY TO CERVICAL CANCER}

According to the postulations of the health belief model, if an individual does not perceive being at risk of having a disease, such a person might not take any protective measures to avert such disease. Individuals have a subjective opinion about their risk of contracting any disease which is from a state of personal conviction (Ajzen, 1998). One of the participants stated that "I don't think I can have cancer since no one in my family has this disease" (African Woman 3). This response is similar to Yep's study (1993) conducted among Asian American students on their perception of HIV/AIDS risk. He found out that Asian American students believe that the HIV/ AIDS epidemic was a non-Asian disease and had low perceived susceptibility to the disease.

Language as a perceived barrier. Knowledge of Polish language was discussed as a main challenge to get informed about cervical cancer screening. This kind of information requires advanced Polish on medical issues. "I am from Egypt, I am still learning Polish and I am a young mother taking care of my kids for now with little time for myself since we arrived here. While in my country, I went for a breast cancer check-up in the hospital when I noticed something strange in my body but it was not any tumour, so going for another screening will increase anxiety in me" (African Woman 1).

\section{SHYNESS TOWARDS CERVICAL CANCER SCREENING}

In this study, it was revealed that not everyone is favourably disposed to exposing their bodies. "I am so shy to go for this kind of screening and medical examination because I would prefer a female doctor to check me" (African woman 9). This is similar to the findings of Jackowska et al. (2012): "Many were surprised that the test is carried out by a nurse or GP, rather than by a gynaecologist as would be the norm in their countries of origin" (p. 233).

Fear and anxiety of screening. All but one of the participants declared their interest in encouraging other women to attend cervical cancer screening in Poland after they had undergone a Pap test. The reason for not being able to recommend a screening test as she recalled is the fact that she does not want to instil fear in the other person who perhaps might be unwilling to attempt it. "It seems painful as I have heard and I don't feel comfortable but maybe if I find someone who has done it before, then I will be motivated" (African Woman 2).

Hospital visit when sick. They do not necessarily visit the hospital when sick as a result of factors ranging from inability to speak Polish, long queues, fear of having to pay for drugs that might not improve state of health, lack of health insurance and proximity of home country and country of residence. Also personal beliefs and experience of hospital and health workers discourage these women from regular visits when ill with minor ailments. One participant believes that she does not necessarily have to visit the hospital and said that "If I fall sick in Poland, I will take care of myself at home since it is not serious and I don't understand the system here in Poland, maybe my friend can help me to translate in the hospital" (African Woman 4).

Lack of information about the availability of screening and screening centres in Poland was amongst the main issues mentioned in the discussion. They do not know about cervical cancer screening methods in general, they did not know if there is a need for such screening in women if there is no sign of such disease, and they do not know about the availability of such centres and procedures in Poland. One participant said: "I have done cancer screening before in my home country more precisely about breast and cervical examination, the result of which was normal" (African Woman 7).

\section{SCREENING IN HOME COUNTRY AND POLAND}

Only one African woman had undergone cervical screening while in her country but was unable to attend another screening since her relocation to Poland. She said "I was advised to continue this test every two years but in a new country now it seems difficult to continue the screening" (African Woman 5).

\section{PERCEPTION OF HEALTH INSURANCE SYSTEM IN POLAND}

The notion of health insurance under the National Health Fund was a strange and unusual topic for the women because they never had prior experience from their country on how this scheme works including the overall benefits (Jackowska et al., 2012). Most foreigners opt for private medical insurance to avoid long waiting periods in the public hospitals. The general perception that there might be an extra fee incurred during a visit to a specialist for cervical cancer screening is common, and this is what one the women said: "I have private medical insurance, and if I have to see a specialist, I would have to pay an extra fee" (African Woman 8). 
Lack of family support. During this discussion, the Egyptian woman cried after narrating her experience because she recounted horrific incidences in her home country, the system and structure of the health care sector and how she lost her husband and all her valuables in the Egyptian crisis in 2011. The lack of emotional support affects women's readiness to adopt healthy behaviour, while on the other hand the presence of family support strengthens health practices, just as one participant said: "Whenever the sickness is beyond a common cold and flu, I prefer to call on my extended family in Germany due to the closeness to Poland and to get some support" (African Woman 6). These kinds of support are related to the cues of action stated in the postulations of the health belief model that requires motivation or advice to undertake a positive health action.

\section{DISCUSSION}

The findings of this study reaffirm the postulations of perceived barriers in HBM that social issues such as migration, cultural beliefs and social relationships prevent women from undertaking cervical cancer screening. As described in this model, a person's belief in the threat of an illness or disease together with such an individual's belief in the effectiveness of the recommended health behaviour or action will predict the likelihood the person will adopt the behaviour. These postulations of the Health Belief Model explain an individual's likelihood to accept or reject a recommended health action like cancer screening and examination. This model has also been used to explain variation in the use of breast cancer screening by different population groups including migrant women in countries such as Australia, Canada, the UK and the USA.

Health information is very important for the adoption of screening programmes by women, since there are loopholes in the understanding of how structures of societies work. It is important to intensify public health campaigns in different languages to create adequate awareness for migrant women living Poland to understand the benefits of Pap test screening.

Cultural differences in migrant women's life style and in the delivery of health services in the home and host country have great influence for acceptance and adoption of cervical cancer screening because they face linguistic, sociocultural and systematic challenges to maintaining healthy behaviour.

This study is not without limitations and challenges in the process of data collection, analysis and interpretation. Some of the participants felt uncomfortable discussing their personal health issues in public. Recording of the discussion was handwritten by each participant in response to the questions from the moderator as some of them objected to both taking of pictures and the audio recording of their voices. This made it a little bit stressful in the gathering of data from these women, and it is proposed that personal interviews should be considered in a subsequent related study.

Notwithstanding the aforementioned limitations, this study was insightful in understanding the experiences of African women in Poland. Future studies could be carried out to compare Polish women and other migrant women to examine their perception and knowledge of cervical cancer screening.

\section{CONCLUSIONS}

This study explored the prevailing sociocultural issues affecting migrant women's health in migration, which seem to have a great influence on acceptance and adoption of cervical cancer screening because they face everyday life difficulties such as linguistic, sociocultural and systematic difficulties preventing them from undertaking cervical cancer screening. Balogun, Odukoya, Oyediran, and Ujomu (2012) attributed the low utilization of cervical cancer screening among women to factors such as low knowledge about the disease, poor health facilities, lack of socioeconomic support, geographical location and changes in one's environment.

It is consistent with previous studies on migrant women's knowledge and perception about cervical cancer screening in host countries. The immigration status of women has been mentioned in studies such as those of Azerkan et al. (2015) and Jackowska et al. (2012) to be one of the reasons for the perceived barrier of migrant women to undertaking screening in host countries.

Therefore, this study proposes that research on migrant women's health in Poland should be initiated in order to direct attention to new areas of cervical cancer screening as there is a growing population of foreigners in Poland and there should be drastic measures to ensure that all categories of women are included in the screening programmes and considering the cost benefits of preventive health for the economy.

\section{ACKNOWLEDGEMENTS}

I am sincerely grateful to my institute, Polish Academy of Sciences, Institute for Philosophy and Sociology, Warsaw, Foundation for Somalia, Warsaw, Poland, for providing the platform to conduct this research and to my supervisor, Prof. Hanna Bojar, for her advisory support in this research project.

Financial support for research projects conducted by doctoral students of the Institute of Philosophy and Sociology of PAN (Grant No: 2/2016).
Migrant women's knowledge and perception of cervical cancer screening in Poland 


\section{REFERENCES}

Afri-Dev info. (2014). Africa cervical cancer incidence \& mortality multi-indicator scorecard. Retrieved from http://www.afri-dev.info/wp-content/uploads/ 2015/07/2014-Africa-Cervical-Cancer-Incidence-Mortality-Multi-Indicator-Scorecard-Fn.pdf

Ajzen, I. (1998). Attitudes, Personality and Behaviour. Chicago, Illinois: The Dorsey Press.

American Cancer Society. (2011). Cancer in Africa. Retrieved from https://www.cancer.org/acs/
Omoye Mary Akhagba groups/content/@epidemiologysurveilance/documents/document/acspc-031574.pdf

American Society for Colposcopy and Cervical Pathology and American Clinical Society. (2012) Retrieved from http://www.guideline.gov/content. aspx?id=36834

Azerkan, F., Widmark, C., Sparén, P., Weiderpass, E., Tillgren, P., \& Faxelid, E. (2015). When life Got in the way: how Danish and Norwegian immigrant women in Sweden reason about cervical screening and why they postpone attendance. PLoS One, 10, e0107624. doi: 10.1371/journal.pone.0107624

Balogun, M. R., Odukoya, O. O., Oyediran, M. A., \& Ujomu, P. I. (2012). Cervical cancer awareness and preventive practices: a challenge for female urban slum dwellers in Lagos, Nigeria. African Journal of Reproductive Health, 16, 75-82.

Bandura, A. (1997). Self-efficacy: The exercise of control. New York: Freeman.

Behavioural risk factor surveillance system. (2012). Retrieved from http://www.cdc.gov/mmwr/preview/ mmwrhtml/mm6122a3.htm?s_cid=mm6122a3_w

Cancer Research UK. (2016). Cervical cancer screening. Retrieved from: http://www.cancerresearchuk.org/about-cancer/type/cervical-cancer/ about/cervical-cancer-screening

Carrie, K., \& Bandolin, S. (2010). Cultural and socioeconomic factors affecting cancer screening, early detection and care in the Latino population. Retrieved from https://ethnomed.org/clinical/cancer/cultural-and-socioeconomic-factors-affecting -cancer-screening-early-detection-and-care-inthe-latino-population.

Centers for Disease Control and Prevention CDC. (CDC vitalsigns) (2014). Cervical Cancer is Preventable. Retrieved from http://www.cdc.gov/vitalsigns/pdf/2014-11-vitalsigns.pdf

Conner, M. (2010). Cognitive determinants of health behaviour. In Handbook of Behavioural Medicine (pp. 19-30). New York: Springer.

Finch, B. K., Frank, R., \& Vega, W. A. (2004). Acculturation and acculturation stress: a social-epidemiological approach to Mexican migrant farmworkers' health. International Migration Review, 38, 236-262. doi: 10.1111/j.1747-7379.2004.tb00195.x

International Agency for Research on Cancer. (IARC, 2005). Cancer prevention. Retrieved from http:// www.iarc.fr/en/publications/pdfs-online/epi/ sp155/index.php

International Agency for Research on Cancer. (IARC, 2012). Cancer. Retrieved from http://www.iarc.fr/ en/publications/pdfs-online/epi/sp155/index.php

International Organization for Migration. (2015). World migration report 2015. Retrieved from https://www.iom.int/world-migration-report-2015

International Organization for Migration. (IOM, 2006). Migration: A social determinant of the health of migrants. Retrieved from http://www.migrant-health-europe.org/files/FINAL\%20DRAFT \%20-\%20IOM\%20SDH.pdf

Jach, R. (2014). Tackling Poland's cervical cancer high mortality rates. Retrieved from http://colposcopycourses.com/tackling-polands-cervical-cancerhigh-mortality-rates-robert-jach-md-phd/

Jackowska, M., VonWagner, C., Wardle, J., Juszczyk, D., Luszczynska, A., \& Waller, J. (2012). Cervical screening among migrant women: a qualitative study of Polish, Slovak and Romanian women in London, UK. The Journal of Family Planning and Reproductive Health Care, 38, 229-238. doi: 10.1136/jfprhc-2011-100144

Januszek-Michalecka, L., Nowak-Markwitz, E., Banach, P., \& Spaczynski, M. (2013). Effectiveness of the National Population-Based Cervical Cancer Screening Programme in Poland-Outcomes, problems and possible solutions years after implementation. Annals of Agricultural and Environmental Medicine, 20, 859-864.

Koutsky, L. (1997) Epidemiology of genital human papillomavirus infection. American Journal of Medicine, 102, 3-8.

Leyden, W. A., Manos, M. M., Geiger, A. M., Weinmann, S., Mouchawar, J., Bischoff, K., Yood, M. U., Gilbert, J., \& Taplin, S. H. (2005). Cervical cancer in women with comprehensive health care access: attributable factors in the screening process. Journal of the National Cancer Institute, 97, 675-683.

Nowakowski, A., Cybulski, M., Śliwczyński, A., Chil, A., Teter, Z., Seroczyński, P., \& Anttila, A. (2015). The implementation of an organised cervical screening programme in Poland: an analysis of the adherence to European guidelines. BMC Cancer, 15, 279. doi: 10.1186/s12885-015-1242-9

Nygård, J. F., Skare, G. B., \& Thoresen, S. Ø. (2002). The cervical cancer screening programme in Norway, 1992-2000: changes in Pap smear coverage and incidence of cervical cancer. Journal of Medical Screening, 9, 86-91.

O’Donnell, C. A., Higgins, M., Chauhan, R., \& Mullen, K. (2008). Asylum seekers' expectations of and trust in general practice: a qualitative study. The British Journal of General Practice, 58, e1-e11. doi: 10.3399/bjgp08X376104

Ostrowska, A. (2007). Cancer of the Cervix. The problem of Medical, Social and Economic. Report of 
a symposium, Warsaw: IFIS SNS Sciences, Daily Health Care.

Quan, H., Fong, A., De Coster, C., Wang, J., Musto, R., Noseworthy, T. W., \& Ghali, W. A. (2006). Variation in health services utilization among ethnic populations. Canadian Medical Association Journal, 174, 787-791. doi: 10.1503/cmaj.050674

Ritchie, J., Spenser, L., \& O'Connor, W. (2003). Carrying out qualitative analysis. In (J. Ritchie \& J. Lewis), Qualitative research practice - a guide for social science students and researchers (pp. 219-262). London: Sage Publications.

Rosenstock, I. M. (1974). Health Belief Model and preventive health behaviour. Health Education Monograph, 4, 354-386.

Samolinski, B. (2012). The Polish perspective: Using innovative approaches to prevent cervical cancer. Retrieved from http://www.ehfg.org/intranet/ app/webroot/uploads/presentations/files/uploads/08e351ecc9014cdc59169c6543d4ee.pdf

Schleicher, E. (2007). Immigrant women and cervical cancer prevention in the United States. Baltimore: WomenLs and ChildrenLs Health Policy Center, Johns Hopkins Bloomberg School of Public Health.

Torres, J. M., \& Wallace, S. P. (2013). Migration circumstances, psychological distress, and self-rated physical health for Latino immigrants in the United States. American Journal of Public Health, 103, 1619-1627.

World Health Organisation. (2014a). Cancer Fact Sheet. Retrieved from http://www.who.int/mediacentre/factsheets/fs297/en/

World Health Organisation. (2014b). Comprehensive Cervical Cancer Control: A guide to essential practice. Second edition. Retrieved from http:// apps.who.int/iris/bitstream/10665/144785/1/ 9789241548953_eng.pdf?ua $=1$

World Health Organisation. (2014c). Early Detection of Cancer. Retrieved from http://www.who.int/ cancer/detection/en/

World Health Organisation. (2014d). Cancer Country Profiles. Retrieved from http://www.who.int/cancer/country-profiles/en/

World Health Organisation. (2014e). Cancer Country Profiles Malawi. Retrieved from http://www.who. int/cancer/country-profiles/mwi_en.pdf?ua $=1$

World Health Organisation. (2014f). Cancer Country Profiles on Poland. Retrieved from http://www. who.int/cancer/country-profiles/pol_en.pdf?ua =1

World Health Organisation. (2010). Challenges facing Health of Migrants to be tackled at key meeting. Retrieved from http://www.who.int/hac/events/ 3march2010/en/

Yep, G. A. (1993). HIV prevention among Asian-American college students: Does the health belief model work? Journal of American College Health, 41, 199-205. 